\title{
Three patterns of nutrient flux in a coral reef community
}

\author{
R. E. Johannes, W. J. Wiebe and C. J. Crossland \\ CSIRO Marine Laboratories, P.O. Box 20, North Beach, Western Australia 6020
}

\begin{abstract}
Dissolved nutrient flux between a coral reef community and the overlying water displayed 3 different patterns: Type 1: Fluxes displayed no diel rhythm but were correlated with ambient dissolved nutrient concentrations. Type 2: Fluxes were not concentration-dependent and exhibited a diel rhythm, net uptake being highest for several hours around mid-day. Type 3: Fluxes displayed neither a measurable diel rhythm nor a correlation with dissolved nutrient concentrations. Our observations suggest that, as dissolved nutrient concentrations increase relative to community nutrient demand, nutrient uptake patterns will shift from Type 2 to Type 2 and subsequently to Type 3 in aquatic communities.
\end{abstract}

\section{INTRODUCTION}

Net fluxes (rates of uptake or release) of nutrients between coral reef communities and overlying waters have been reported by Pilson and Betzer (1973), Webb et al. (1975) and Atkinson (1981). These studies were conducted on relatively low latitude reef communities

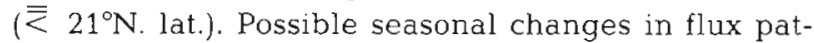
terns were not examined. Here we report on the fluxes of dissolved nutrients in a high latitude coral reef community (28 $\mathrm{S}$. lat.) during both September 1979 and March 1980. These times were chosen to coincide roughly with periods of minimum and maximum water temperatures - ca. $18^{\circ}$ and $26^{\circ} \mathrm{C}$ respectively (Johannes et al., 1983).

The study community displayed 3 distinct patterns of nutrient flux. We describe these patterns and discuss the conditions under which each occurred.

\section{RESEARCH SITE}

The studies took place in the Easter group, Abrolhos Islands, about $60 \mathrm{~km}$ off the coast of Western Australia. These islands contain the southernmost coral reefs in the Indian Ocean. Their biological characteristics have been described by Wilson and Marsh (1980). The biota is a mixture of tropical and temperate forms. Coral growth is luxuriant in some areas and 39 genera have been identified (Wilson and Marsh, 1980; Marsh, pers. comm.).
Our study site was a flat-topped coral reef community on a lagoonal mound rising from a 3 to $5 \mathrm{~m}$ deep sand bottom. Corals (primarily branching and tabular Acropora) covered about $75 \%$ of the reef area. Rock and sand patches, some with fairly abundant stands of brown algae (Turbinaria and Sargassum) were also present. The reef community was roughly rectangular, with a mean width of $120 \mathrm{~m}$ and a mean length of $450 \mathrm{~m}$. The tops of the corals in this community are occasionally exposed during periods of extreme low tides. During the study periods described here corals were not exposed. During the March study mean water depth was $62 \mathrm{~cm}$ (range 40 to $90 \mathrm{~cm}$ ). During the September study mean water depth was $48 \mathrm{~cm}$ (range 27 to $95 \mathrm{~cm}$ ).

The studies were part of a larger investigation of community metabolism at the site. A concurrent study by Smith (1981) revealed unusually high rates of community calcification and primary productivity relative to other coral reef communities. Rates of total community calcification and community primary productivity showed considerable seasonal variation (Smith, 1981) as did calcification rates of two species of corals growing near the study site (Crossland, 1982).

\section{METHODS}

Water masses were sampled as they moved from the lagoon onto the reef and at the termination of their path across the reef. This was accomplished by follow. 
ing drogues consisting of neutrally buoyant, waterfilled plastic bottles as they crossed the reef. Many transects were run in duplicate by pairs of observers following drogues released several tens of meters apart. Water depth was measured once per minute along each transect. Water samples were filtered through a $0.45 \mu \mathrm{m}$ pore glass fibre filter and frozen for later nutrient analysis.

Standard methods for seawater analysis (Strickland and Parsons, 1972) were modified for use with small sample volumes (5 to $10 \mathrm{ml}$ ). Nitrate was measured as nitrite after reduction in a copperized cadmium column (10 cm $\times 4 \mathrm{~mm}$ diam.) (Wood et al., 1967). Dissolved organic phosphorus (DOP) was estimated according to Menzel and Corwin (1965), and dissolved organic nitrogen (DON) according to D'Elia et al. (1977). Optical density determinations were made with $5 \mathrm{~cm}$ light-path cuvettes.

Net fluxes of dissolved nutrients between water and benthic community were calculated as change in dissolved nutrient concentration per unit time, multiplied by mean transect water depth during the sampling period.

\section{RESULTS}

The direction of water movement across the reef varied with wind direction and tidal stage. Collectively, therefore, our transects sampled a large area rather than consistently sampling the same line across the reef. The distance travelled by a body of water moving across the reef varied with current direction because of the rectangular shape of the reef. Water transit times varied from 11 to $82 \mathrm{~min}$. Studies with fluorescein dye showed that lateral eddy diffusion was minimal; our drogues stayed within the same discrete water masses during their passage across the reef. Turbulent mixing of water from top to bottom was very rapid relative to water transit times across the reef, ensuring that no stratification of nutrients occurred.
We did not measure current velocities during the study, but they appeared to vary more or less directly with tidal height. No significant correlations were found between tidal heights and nutrient flux rates.

\section{Upstream nutrient concentrations}

Dissolved nutrient concentrations were lower in March than in September, except for $\mathrm{NO}_{2}^{-} \mathrm{DOP}$ and $\mathrm{SiO}_{4}^{2-}$, of which mean concentrations were not significantly different statistically during the 2 periods (Table 1). In One Tree Reef Lagoon, Great Barrier Reef, Hatcher and Hatcher (1982) found similarly that concentrations of total dissolved inorganic nitrogen were lower in late summer than in late winter.

Nutrient concentrations in water moving from the lagoon onto the reef community varied significantly within both March and September sampling periods (see ranges in Table 1). The cause of these fluctuations is not known. The complex of reefs, channels and lagoonal areas surrounding the study site undoubtedly generates complex currents and probably causes water masses with different metabolic histories and thus different nutrient concentrations to impinge upon the study site as tide and wind conditions change. Whatever the reason, this variability in incoming nutrient concentrations enabled us to identify one of the patterns of nutrient flux described below.

\section{September (late winter) nutrient flux patterns}

In September net community uptake of $\mathrm{NH}_{4}^{+}, \mathrm{NO}_{2}^{-}$, inorganic phosphate (DIP) and DOP occurred for several hours during the middle of the day. As an example, $\mathrm{NH}_{4}^{+}$flux data are shown in Fig. 1. Here the period during which net community uptake occurred continuously was from about 1100 to 1500 local time. For other nutrients the periods of continuous net uptake were:

Table 1. Dissolved nutrient concentrations $\left(\mu\right.$ moles $\left.l^{-1}\right)$ in water impinging upon the reef community

\begin{tabular}{|c|c|c|c|c|}
\hline \multirow[t]{2}{*}{ Nutrient } & \multicolumn{2}{|c|}{ September } & \multicolumn{2}{|c|}{ March } \\
\hline & Mean $^{d}$ & Range & Mean $^{a}$ & Range \\
\hline $\mathrm{NO}_{3}^{-}$ & $1.17(0.08)$ & $0.69-2.0$ & $0.90(0.04)$ & $0.47-1.8$ \\
\hline $\mathrm{NO}_{2}^{-}$ & $0.037(0.003)$ & $0.017-0.081$ & $0.058(0.01)$ & $0.002-0.32$ \\
\hline $\mathrm{NH}_{4}^{+}$ & $0.296(0.09)$ & $0.006-1.97$ & $0.024(0.005)$ & $0-0.123$ \\
\hline $\mathrm{DON}^{\mathrm{b}}$ & $10.7(0.54)$ & $6.1-20.7$ & $8.7(0.52)$ & $3.0-21.9$ \\
\hline $\mathrm{DIP}^{\mathrm{b}}$ & $0.375(0.075)$ & $0.039-1.87$ & $0.21(0.03)$ & $0-0.84$ \\
\hline$D^{b}$ & $0.35(0.05)$ & $0.14-1.0$ & $0.36(0.04)$ & $0.037-1.6$ \\
\hline $\mathrm{SiO}_{4}^{2-}$ & $2.32(0.10)$ & $1.3-3.2$ & $2.21(0.13)$ & $0.67-4.1$ \\
\hline
\end{tabular}




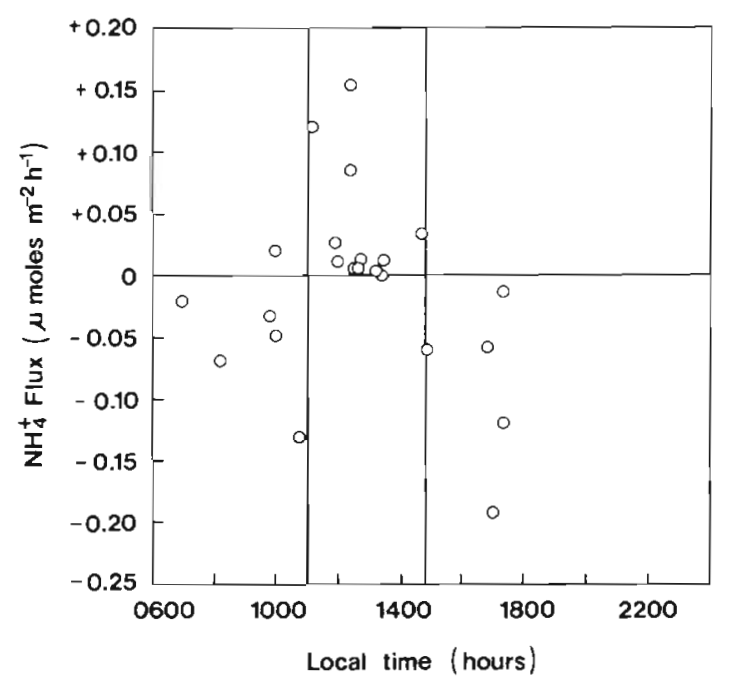

Fig. 1. $\mathrm{NH}_{4}^{+}$flux on coral community transect in September. Positive values indicate net community uptake; negative values, net community release

$\mathrm{NO}_{2}^{-}-0700$ to 1200 local time; DIP -1000 to 1230 local time; DOP -1000 to 1300 local time. Mean net release of these nutrients occurred during the rest of the sampling period (e.g. Fig. 1). Similarly, instantaneous net community productivity was positive from about 1000 to 1500 local time, and otherwise negative (Smith, 1981). For the study period as a whole there was a net loss from the community of all dissolved nutrients except $\mathrm{NO}_{2}^{-}$and $\mathrm{NO}_{3}^{-}$, mean net fluxes, which did not differ statistically from zero (Table 2).

Nitrate fluxes exhibited no diumal trend, but fluctuated rapidly in sign and magnitude throughout the sampling period. An analysis of regression (Model II, Ricker, 1973; Laws and Archie, 1981) revealed a weak but statistically significant correlation between $\mathrm{NO}_{3}^{-}$ fluxes and incoming $\mathrm{NO}_{3}^{-}$concentrations $(\mathrm{r}=0.39$,

Table 2. Sign of mean net community fluxes in coral community during study periods

\begin{tabular}{|ccc|}
\hline Nutrient & September & March \\
\hline $\mathrm{NO}_{3}^{-}$ & 0 & + \\
$\mathrm{NO}_{2}^{-}$ & 0 & + \\
$\mathrm{NH}_{4}^{+}$ & - & + \\
$\mathrm{DIP}$ & - & + \\
$\mathrm{DOP}$ & - & + \\
$\mathrm{DON}$ & - & + \\
$\mathrm{SiO}_{4}^{2-}$ & - & + \\
Net community uptake & \\
- Net community release & \\
O Mean flux not significantly different from O \\
\hline
\end{tabular}

$p<0.05$ ). No such correlation was found for other nutrients during the September sampiing period.

Fluxes of $\mathrm{SiO}_{4}^{2-}$ and DON showed neither a diurnal rhythm nor a significant correlation with incoming concentrations.

\section{March (late summer) nutrient flux patterns}

Nutrient fluxes in March showed no diurnal trend. As an example, changes in rates of net uptake or release of $\mathrm{NH}_{4}^{+}$by the reef community are shown in Fig. 2. As with other nutrients $\mathrm{NH}_{4}^{+}$flux varied rapidly

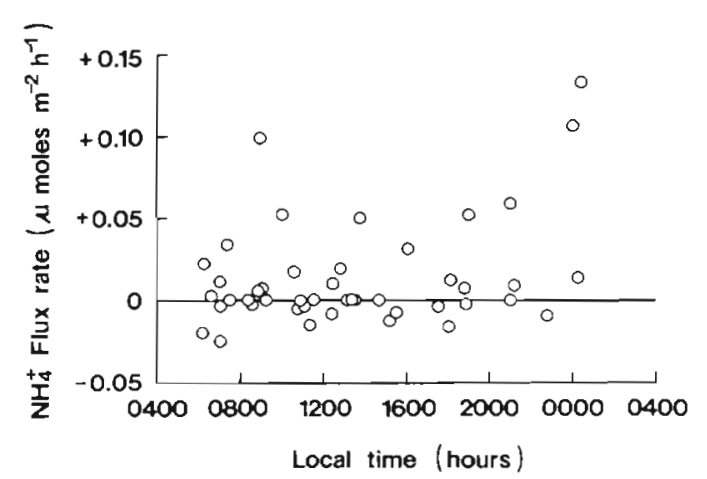

Fig. 2. $\mathrm{NH}_{4}^{+}$flux on coral community transect in March. Positive values indicate net community uptake; negative values, net community release

Table 3. Significant coefficients of correlation for flux rates vs. upstream concentrations of dissolved nutrients on coral transect

\begin{tabular}{|ccc|}
\hline Nutrient & September & March \\
\hline $\mathrm{NO}_{3}^{-}$ & $+0.39^{+}$ & $+0.58^{+}$ \\
$\mathrm{NO}_{2}^{-}$ & - & $+0.41^{++}$ \\
$\mathrm{NH}_{4}^{+}$ & - & $+0.87^{++}$ \\
$\mathrm{DIP}$ & - & $+0.45^{++}$ \\
$\mathrm{DOP}$ & - & $+0.70^{++}$ \\
$\mathrm{DON}$ & - & - \\
$\mathrm{SiO}{ }_{4}^{2-}$ & - & - \\
+ Significant at $\mathrm{p}<0.05$ & \\
++ Significant at $\mathrm{p}<0.01$ & \\
- Correlation not statistically significant, $\mathrm{p}>0.05$ \\
\hline
\end{tabular}

in sign and magnitude throughout the study period. Attention is drawn to the marked differences between the flux trends for $\mathrm{NH}_{4}^{-}$in March (Fig. 2) and September (Fig. 1).

Fluxes of $\mathrm{NH}_{4}^{+}$in September (Fig. 3) were correlated with incoming ambient concentrations $(r=0.89$, $\mathrm{p}<0.01)$. Significant correlations between fluxes and 
incoming dissolved nutrient concentrations $(p<0.01)$ were also found for $\mathrm{NO}_{3}^{-}, \mathrm{NO}_{2}^{-}, \mathrm{NH}_{4}^{+}$, DIP and DOP (Table 3). Over the study period the mean net flux of all these nutrients, in contrast to September was positive; that is, there was a net uptake by the reef community (Table 2).

As in September, the fluxes of $\mathrm{SiO}_{4}^{2-}$ and DON showed neither diurnal trends nor a significant correlation with incoming concentrations. In contrast to September, however, there was a net uptake of these nutrients by the community over the study period.

\section{DISCUSSION}

The net uptake of total dissolved nitrogen, total dissolved phosphorus and dissolved silicate by the reef community in March and the net release of these nutrients in September is consistent with community $\mathrm{P} / \mathrm{R}$ ratios during these sampling periods. In March the community had a P/R ratio of 1.07 (Smith, 1981) implying a net increase in biomass and thus a probable increase in associated nutrients. In September the $P / R$ ratio was 0.84 implying a net loss of biomass and thus a probable loss of associated nutrients.

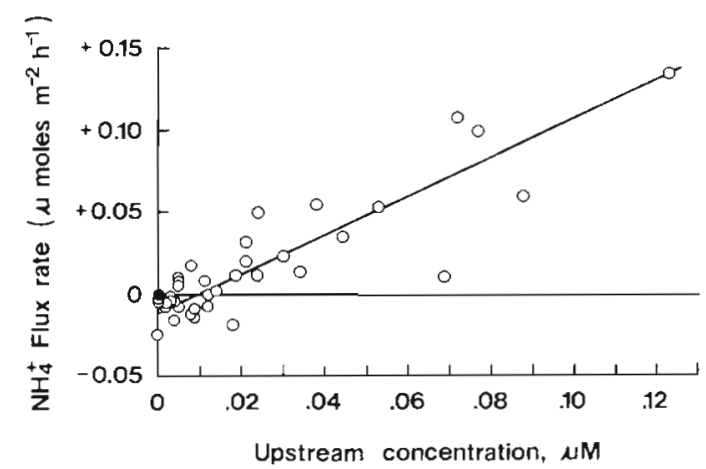

Fig. 3. Regression of $\mathrm{NH}_{4}^{+}$flux in March on upstream $\mathrm{NH}_{4}^{+}$ concentration. Positive values indicate net community uptake; negative values, net community release. $\mathrm{r}=.87, \mathrm{p}<.01$

Each of the 14 patterns of nutrient flux between the reef community and the overlying water can be resolved into one of three distinct types (Table 4).

Type 1. Fluxes display no diurnal rhythms and are correlated with ambient dissolved nutrient concentrations (March; $\mathrm{NO}_{3}^{-}, \mathrm{NO}_{2}^{-}, \mathrm{NH}_{3}^{-}$DIP, DOP. September; $\mathrm{NO}_{3}^{-}$). There was a net uptake of these nutrients by the community during the sampling period. Equations for Type 1 flux patterns, describing the regression of nutrient flux on incoming nutrient concentrations, enabled us to calculate zero net flux (ZNF) concentrations. These are the dissolved nutrient concentrations
Table 4. Nutrient flux patterns on the reef community

\begin{tabular}{|lcc|}
\hline Nutrient & September & March \\
\hline $\mathrm{NO}_{3}^{-}$ & 1 & 1 \\
$\mathrm{NO}_{2}^{-}$ & 2 & 1 \\
$\mathrm{NH}_{4}^{+}$ & 2 & 1 \\
$\mathrm{DIP}$ & 2 & 1 \\
$\mathrm{DOP}$ & 2 & 1 \\
$\mathrm{DON}$ & 3 & 3 \\
$\mathrm{SiO}{ }_{4}^{2-}$ & 3 & 3 \\
& & \\
Community uptake rates showed no diel rhythm but \\
were correlated with ambient dissolved nutrient con- \\
centrations \\
2 Net community fluxes were positive for several h \\
around mid-day, otherwise negative. Rates were not \\
correlated with ambient dissolved nutrient concentra- \\
tions \\
3 Net community fluxes exhibited neither a diel rhythm \\
nor a correlation with ambient dissolved nutrient con- \\
centrations
\end{tabular}

at which net flux between the reef community and the overlying water would be zero. An example is provided in Fig. 3: the ZNF is the upstream concentrations at the point where the regression line intersects the zero-net-flux line. ZNF concentrations (in $\mu \mathrm{M}$, with standard errors of the means in parentheses) are:

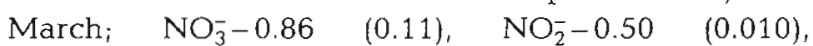
$\mathrm{NH}_{4}^{+}-0.016(0.0043)$, DIP -0.15 (0.033), DOP -0.20 $(0.049)$. September; $\mathrm{NO}_{3}^{-}-1.15(0.20)$.

Type 2. Net uptake of nutrients by the community occurs for a few hours around mid-day for periods similar in time and duration to those during which net community productivity is positive. Net productivity and net community fluxes of nutrients are both negative at other times of the day and for the sampling period as a whole. Fluxes are not correlated with ambient dissolved nutrient concentrations (September; $\mathrm{NO}_{2}^{-}, \mathrm{NH}_{4}^{+}$, DIP and DOP).

Type 3. Fluxes display neither a diel rhythm nor a correlation with ambient dissolved nutrient concentrations (September and March, DON and $\mathrm{SiO}_{4}^{2-}$ ). Under Type 3 conditions net fluxes were negative in September and positive in March (Table 2).

What we refer to here as Type 1 and Type 2 patterns of nutrient uptake seem to have been detected in other coral reef communities. Atkinson (1981) found that uptake of DIP in an experimental coral reef community displayed no diel rhythm and was concentrationdependent. Similarly Pilson and Betzer (1973) did not detect a diel rhythm of DIP flux in 2 Enewetak reef communities. An analysis of variance of the larger of their 2 data sets (Pilson and Betzer, 1973: Table 2, p. $583)$ suggests that flux rates may have been concentra- 
tion-dependent: For DIP, $\mathrm{r}=0.44, \mathrm{p}<0.07$; for DOP, $r=0.48, p<0.07$. Henderson (1982) could identify no diurnal pattern of flux of dissolved nitrogen or phosphorus compounds in microcosm and in situ studies of reef flat communities. In contrast, Webb et al. (1975) reported a diurnal rhythm in the flux of dissolved nitrogen compounds in 2 Enewetak reef communities.

It might be expected that light and ambient dissolved nutrient concentration would influence the rate of nutrient uptake by a community simultaneously. Our data provide no evidence for this. What explanation can we give for a community in which nutrient concentration exerts a major influence on community nutrient flux (Type 1 pattern) under some conditions, light apparently exerts a major influence (Type 2 pattern) under other conditions, and uptake rates are correlated with neither variable (Type 3 pattern) under still other conditions?

A number of reports indicate that light stimulates phosphate uptake in marine phytoplankton and macroalgae at high DIP concentrations, but that such stimulation is reduced or absent at low DIP concentrations (reviewed by Healey, 1973, and Lemasson et al., 1980). Similarly, Malone et al. (1975) found that nitrate uptake by the phytoplankter Chaetoceros sp. was concentration-dependent and independent of the lightdark cycle at low nitrate concentrations; at high nitrate concentrations, in contrast, nitrate uptake peaked during the early hours of daylight. To explain such observations, Healey (1973) suggested that dark respiration may provide sufficient energy to support the maximum rate of DIP uptake by algae at uptake-limiting DIP concentrations, but not at higher, non-limiting concentrations. The same explanation may also hold for uptake patterns of dissolved nitrogen compounds.

These considerations lead us to suggest that concentration-dependent (Type 1) nutrient flux occurred in our study community when a nutrient was present, on the average, at low concentrations relative to community demand. We are tempted to say 'at near-limiting concentrations', but there is no information available on just what nutrient-limiting concentrations are in coral reef communities. The Type 1 pattern occurred in summer when community productivity was relatively high (Smith, 1981) and nutrient concentrations relatively low (Table 1). In situ $\mathrm{N}$ limitation has been reported for temperate macroalgae during the summer when nitrogen concentrations were low and algal productivity was high (e.g. Topinka and Robbins, 1976; Chapman and Craigie, 1977; Hanisak, 1979).

Light-dependent nutrient fluxes (Type 2) apparently occur at the study site when a nutrient is present in moderately high concentrations. Light-enhanced uptake of nutrients occurred in September when the concentrations of these nutrients were higher than in
March (Table 1) and community productivity was lower (Smith, 1981), suggesting that the community had lower nutrient requirements.

Uptake rates of nutrients showing no measurable diel rhythm nor a correlation with dissolved nutrient concentration (Type 3 pattern) occurred, we suggest, when the nutrient was present in concentrations that were very high relative to community demand, thereby masking any measurable diel flux rhythm. If this interpretation is correct, the Type 3 pattern is really a special variation of the Type 2 pattern and the difference between the 2 patterns will be defined by the frequency of sampling and precision of analyses rather than by qualitative differences in uptake mechanisms. In other words, had we sampled with sufficient frequency and analyzed the nutrients with sufficient precision we might have been able to detect a diel flux rhythm for $\mathrm{SiO}_{4}^{2-}$ and DON. An alternative hypothesis is that diel flux rhythms cease to exist at high nutrient concentrations and that the Type 3 pattern involves some physiological shift in uptake kinetics, making it fundamentally distinct from the Type 2 flux pattern.

\section{CONCLUSIONS}

Our data demonstrate for the first time 3 patterns of nutrient flux in a single benthic community - a concentration-dependent pattern, a diel pattern and a pattern that is not measurably related to either light or changing nutrient concentration. The data also demonstrate that all 3 patterns can occur simultaneously for different nutrients in a community, and that, for an individual nutrient, the pattern may shift with time (Table 4)

Our explanation for these patterns remains speculative, although, as discussed above, there is support in the literature for our interpretation of diel and concentration-dependent patterns. It was not practical to manipulate the whole reef community in such a way as to test these ideas, although this could be done using flow-through benthic microcosms (e.g. Atkinson, 1981). We invite other investigators to test our hypothesis; we do not have the appropriate facilities. If nutrient uptake patterns in benthic communities shift from Type 1 to Type 2 and ultimately to Type 3 as dissolved nutrient concentrations increase relative to nutrient demand, this phenomenon might be used to monitor the degree of eutrophication of benthic communities. For example, a sustained shift from Pattern.2 to Pattern 3 in the flux of inorganic phosphorus or nitrogen compounds in benthic communities exposed to nutrient enrichment, as from sewage discharge, might provide an early indication of impending hypertrophication. 
Acknowledgements. We thank Steve Smith, Marlin Atkinson and Bruce and Annamarie Hatcher. Discussions with them helped significantly in shaping this paper

\section{LITERATURE CITED}

Atkinson, M. J. (1981). Phosphate metabolism of coral reef flats. Ph. D. thesis, University of Hawaii

Chapman, A. R. O., Craigie, J. S. (1977). Seasonal growth in Laminaria longicruris: relations with dissolved inorganic nutrients and internal reserves of nitrogen. Mar. Biol. 40: 197-205

Crossland, C. J. (1982). Seasonal growth of Acropora cf. formosa and Pocillopora damicornis on a high latitude reef (Houtman Abrolhos, Western Australia). In: Gomez, E. D. (ed.) Proceedings of the Fourth International Coral Reef Symposium. University of Philippines, Manila, p. 663-667

D'Elia, C. F., Steudler, P. A., Corwin, N. (1977). Determination of total nitrogen in aqueous samples using persulphate digestion. Limnol. Oceanogr, 22: 760-764

Hanisak, M. D. (1979). Nitrogen limitation of Codium fragile spp. tomentosoides as determined by tissue analysis. Mar. Bioi. 50: 333-337

Hatcher, A. I., Hatcher, B. G. (1982). Seasonal and spatial variation in dissolved inorganic nitrogen in One Tree Reef Lagoon. In: Gomez, E. D. (ed.) Proceedings of the Fourth International Coral Reef Symposium. University of Philippines, Manila, p. 419-424

Healey, F. P. (1973). Inorganic nutrient uptake and deficiency in algae. CRC crit. Rev. Microbiol. 3: 69-113

Henderson, R. S. (1982). In situ and microcosm studies of diel metabolism of reef flat communities. In: Gomez, E. D. (ed.) Proceedings of the Fourth International Coral Reef Symposium. University of Philippines, Manila, p. 679-686

Johannes, R. E., Wiebe, W. J., Crossland, C. J., Rimmer, D.W., Smith, S. V. (1983). Latitudinal limits of coral reef growth. Mar. Ecol. Prog. Ser. 11: 105-111
Laws, E. A., Archie, J. W (1981). Appropriate use of regression analysis in marine biology. Mar. Biol. 65: 13-16

Lemasson, L., Pagès, J., Cremoux, J.-L. (1980). Inorganic phosphate uptake in a brackish tropical lagoon. Estuar. coast. mar Sci. 11: 547-561

Malone, T. C., Garside, C., Haines, K. C., Roels, O. A. (1975). Nitrate uptake and growth of Chaetoceros sp. in large outdoor continuous cultures. Limnol. Oceanogr 20: 9-19

Menzel, D. W., Corwin, N. (1965). The measurement of total phosphorus in seawater based on the liberation of organically bound fractions by persulphate oxidation. Limnol. Oceanogr. 10: 280-282

Pilson, M. E. Q., Betzer, S. B. (1973). Phosphorus flux across a coral reef. Ecology 54: 581-588

Ricker, W. E. (1973). Linear regressions in fishery research. J. Fish. Res. Bd Can. 30: 409-434

Smith, S. V. (1981). The Houtman Abrolhos Islands: carbon metabolism of coral reefs at high latitude. Limnol. Oceanogr. 26: 612-621

Strickland, J. D. H., Parsons, T. R. (1972). A practical handbook of seawater analysis (2nd ed.). Bull. Fish. Res. Bd Can. 167: 1-311

Topinka, J. A., Robbins, J. V. (1976). Effects of nitrate and ammonium enrichment on growth and nitrogen physiology in Fucus spiralis. Limnol. Oceanogr. 21: 659-664

Webb, K. L., DuPaul, W. D., Wiebe, W., Sottile, W., Johannes, R. E. (1975). Enewetak (Eniwetok) Atoll: aspects of the nitrogen cycle on a coral reef. Limnol. Oceanogr. 20: 198-210

Wilson, B. R., Marsh, L. M. (1980). Coral reef communities at the Houtman Abrolhos, Western Australia, in a zone of biogeographic overlap. In: Proc. Symp. Marine Biogeographic Evolution in the Southern Hemisphere, Auckland, 1978 , p. $259-278$

Wood, E. D., Armstrong, F. A. J., Richards, F. A. (1967). Determination of nitrate in seawater by cadmium-copper reduction to nitrite. J. mar. biol. Ass. U. K. 47: 23-31 